\title{
Os termos de emoção no acórdão do pedido de soltura de José Dirceu na Operação Lava Jato e as Representações Textual- Discursivas
}

\section{Fernanda Isabela Oliveira Freitas}

Doutoranda em Estudos da Linguagem pela Universidade Federal do Rio Grande do Norte (UFRN), Brasil. Bolsista CAPES, processo n.001.

professorafernanda.isabela@hotmail.com

\section{Luis Álvaro Sgadari Passeggi}

Professor Titular da Universidade Federal do Rio Grande do Norte (UFRN), Brasil. luispasseggi.ufrn@gmail.com

Resumo: As emoções no direito nos levam a depreender que o embate discursivo envolve o ethos, o logos e o pathos, este não restrito a emoções psicológicas, mas signos transportadores de sentidos reconhecidos pelo outro sujeito da comunicação/relação. A partir da relação entre as emoções, a Representação Textual-Discursiva (Rtd) e o discurso jurídico no viés da argumentação, dispomos a compreender e relacionar esses fenômenos materializados no acórdão do pedido de soltura de José Dirceu na Operação Lava Jato, baseados em Adam (2011, 2015), Bazerman (2011), Grize (1990, 1996) e Plantin (2010, 2011). Destarte, percebemos que o material linguisticamente utilizado na construção do texto desse gênero como ação social, o valor argumentativo das Rtd e os termos de emoção se fazem presentes em virtude do propósito dessa ação de linguagem no contexto jurídico.

Palavras-chave: Emoção. Representação textual-discursiva. Acórdão. Argumentação.

\begin{abstract}
The emotions in law lead us to realize that the discursive struggle enfolds the ethos, logos and pathos, not restricted by psychological emotions, but through signs capable of transfer meaning to the other subject of communication / relationship. From the relationship between emotions, the Discursive Textual Representation (Rtd) and the legal discourse in the bias of the argumentation, we are able to understand and relate these phenomena materialized in the judgment of José Dirceu's request for release in Operation Lava Jato, based on Adam (2011, 2015), Bazerman (2011), Grize (1990, 1996), and Plantin (2010, 2011). Thus, we see that the material linguistically used in the construction of the text of this genre as social action, the argumentative value of RTD and the terms of emotion are present because of the purpose of this action of language in the legal context.
\end{abstract}

Keywords: Emotion. Textual-discursive representation. Judgment. Argumentation. 
Introdução

A visão aristotélica evidencia o discurso ou a argumentação a partir de três componentes: o logos diz respeito à argumentação racional propriamente dita; o pathos, por sua vez, corresponde ao envolvimento e ao convencimento do interlocutor; finalmente, o ethos, que se refere ao aspecto ético ou moral que o enunciador deixa entrever em seu discurso a fim de garantir o sucesso da oratória. Retomando dois pólos da retórica clássica dos estudos da argumentação, Amossy (2005) ressalta o ethos - a construção da imagem de si que o orador projeta em seu discurso - e o pathos - a construção discursiva da emoção que ele quer suscitar em seu auditório e que também deve ser construída discursivamente.

No contexto jurídico, as emoções nos levam a entender que o embate discursivo do direito envolve, além do ethos, que seria não só SER, mas tem que PARECER; o logos, a razão, que seria o mais sublime, alvo de todo jurista; e o Pathos, não emoções psicológicas, humores, mas signos transportadores de sentidos reconhecidos pelo outro sujeito da comunicação/relação.

Acreditamos, ainda, que "[...] todo texto constrói, com menor ou maior explicitação, uma representação discursiva do seu enunciador, de seu ouvinte ou leitor e dos temas ou assuntos que são tratados" (RODRIGUES; PASSEGGI; SILVA NETO, 2010, p. 173). A representação discursiva do enunciador é a representação de si, nos seus diferentes níveis; a representação discursiva do(s) ouvinte(s) consiste na representação do interlocutor ou dos interlocutores; já a representação discursiva dos temas tratados ancora-se dos diferentes temas ou tópicos abordados. Essa Representação textual-discursiva (Rtd) está vinculada a uma argumentação onipresente, que nas palavras de Grize (1990), são operações de textualização que as esquematizações (representações discursivas) produzem, como plenamente argumentativas.

Essa perspectiva teórica da Rtd com valor argumentativo nos instigou a propor uma articulação entre a Rtd e as emoções, relacionando elementos do discurso, do texto e da argumentação, que compõem tanto a Rtd com valor argumentativo, como as emoções no discurso jurídico.

A partir da relação entre as emoções, a Rtd e o discurso jurídico no viés da argumentação, o objetivo geral deste estudo foi analisar as Representações textual-discursivas (Rtd) com valor argumentativo e a sua articulação com os termos de emoções. Para isso, identificamos a relação 
entre as Rtds construídas do réu José Dirceu e os termos de emoções e compreendemos o funcionamento textual do valor argumentativo da Rtd a partir dos termos de emoção no acórdão do pedido de habeas corpus (TRF da

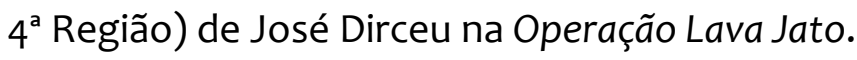

Para tanto, realizamos uma pesquisa descritiva quanto aos objetivos, por descrever as características de determinados fenômenos (GIL, 2010). E documental quanto aos procedimentos, por utilizar materiais que carecem de tratamento analítico ou os que podem ser revisitados para atender aos objetos da pesquisa a partir de técnicas, etapas e procedimentos apropriados, considerando serem fontes primárias (dado original), (LAMY, 2011). Em vista disso, a abordagem foi qualitativa e de natureza interpretativista através do método indutivo definido como "[...] uma ferramenta que conduz o pesquisador(a) a observar a realidade para fazer seus experimentos e tirar suas conclusões" (OLIVEIRA, 2013, p. 50-51).

Em primeiro momento, discutiremos a abordagem teórica da Análise Textual dos Discursos (ATD) de Adam (2011) a partir dos níveis ou planos de análise, centrando - se na Representação Textual-Discursiva com valor argumentativo e a caracterização do gênero acórdão como ação social. Em segundo momento, será realizada a análise das Rtds do réu José e os termos de emoção no acórdão do pedido de soltura de José Dirceu na Operação Lava Jato. Ao final, figurarão as conclusões das análises.

\section{As representações textuais-discursivas com valor argumentativo}

A Análise Textual dos Discursos constitui uma abordagem teórica e descritiva de estudos linguísticos do texto, pautada, “[...] na perspectiva de um posicionamento teórico e metodológico que [...] situa decididamente a linguística textual no quadro mais amplo da análise do discurso" (ADAM, 2011, p. 24).

A partir dessa correlação, Adam (2011, p. 63) propõe uma Análise Textual dos Discursos que visa a "[...] teorizar e descrever os encadeamentos de enunciados elementares no âmbito da unidade de grande complexidade que constitui um texto". Nesses termos, recorrendo a elementos da análise de discurso e da linguística de texto, Adam (2011) propõe à Análise Textual dos Discursos o papel de descrever, definir e analisar diferentes unidades ou operações textuais, inclusive aquelas de níveis mais complexos, que são realizadas sobre os enunciados. Esses níveis de análise (níveis ou planos de 
análise de discurso e análise textual - linguística textual) são apresentados por Adam (2011) na figura 1, a seguir:

Figura 1 - Esquema 04

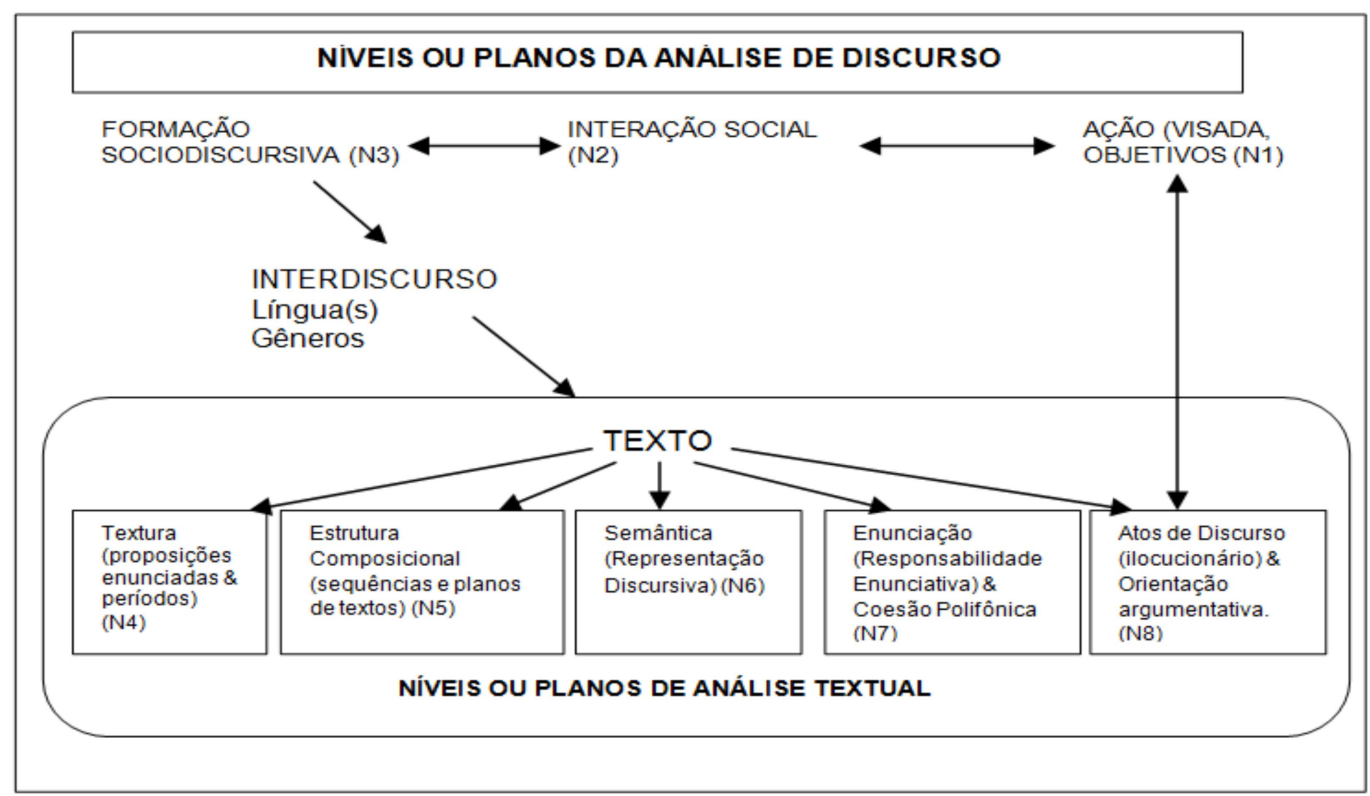

Fonte: Adam (2011, p. 61)

Nessa perspectiva, Passeggi (2016, p. 2886) adapta os níveis de análise textual propostos por Adam (2011), redistribuindo seus conteúdos em um conjunto de módulos que compreende - principalmente, mas não exclusivamente-os citados, sucintamente caracterizados, a seguir:

\footnotetext{
- Módulo Sequencial-composicional (enunciados, períodos, sequências, planos de texto);

- Módulo Enunciativo (responsabilidade enunciativa, pontos de vista);

-Módulo Semântico (representações discursivas, papéis semânticos, anáforas, isotopias, colocações);

- Módulo Argumentativo (atos ilocucionários, orientação argumentativa).
}

Esses módulos se organizariam conforme ligações textuais em três níveis, quais sejam: ligações microtextuais - conexidade; ligações mesotextuais - coesão, "[...] sentimento de totalidade local e global, das partes em si mesmas e das partes em relação ao todo textual” (ADAM, 2015, p. 45) e ligações macrotextuais - "[...] sentimento de adequação dos enunciados em relação a uma situação sociodiscursiva e em relação a um gênero de discurso" (Ibidem, p. 46). 
Vale salientar que Passeggi (2016, p. 2887) assevera concebermos “[...] os módulos como distintos, mas não encapsulados, posto que devem interagir". Isto porque, a articulação entre ambos os níveis, sempre deve ser levada em conta no momento da análise, conforme sugerem as setas presentes no Esquema 4 (Figura 1).

A partir desse contexto, as categorias que utilizamos para analisar as Rtd do réu na Operação Lava Jato foram: a referenciação, que consiste na designação dos referentes do texto, com especial atenção para os processos de redesignação e para as cadeias de referenciação assim constituídas. A segunda foi a predicação, que remete tanto à operação de seleção dos predicados, isto é, à designação dos processos, no sentido amplo (ações, estado, mudanças de estado), como ao estabelecimento da relação predicativa do enunciado, sendo responsável por atribuir sentidos a elementos constantes no enunciado (RODRIGUES et al., 2010, p. 17). Por fim, a modificação, que é definida por Queiroz (2013, p. 67) como categoria que apresenta as propriedades ou qualidades tanto dos referentes como das predicações, desempenhando função atributiva e qualificadora, contribuindo para a construção do objeto referenciado.

Em nossa pesquisa, focalizamos o nível semântico e o argumentativo da análise textual. Considerando que a própria Rtd é argumentação a partir dos postulados de Grize (1990, 1996), ao afirmar que a esquematização é, na verdade, uma organização do material verbal em uso numa dada comunicação, visando a uma construção de sentidos que atinja um produto discursivo - esperado.

Para entender melhor a representação discursiva, Rodrigues, Passeggi e Silva Neto (2010, p. 174) ressaltam que uma das noções que estão na base - na ATD - da elaboração da representação discursiva é a esquematização de J-B. Grize (1990, 1996). Para esse autor, todo texto propõe uma "esquematização", realizada a partir de operações sobre os objetos de discurso e o sujeito, considerando-se o interlocutor na interação.

Passeggi (2001, p. 249) afirma que "[...] toda esquematização contém imagens que, na terminologia de Grize, são os elementos visíveis no texto para um observador, ressalvadas as interpretações possíveis". Com isso, entendemos que A constrói (esquematiza), por meio de enunciados, uma representação discursiva através de objetos de discurso que são postos em jogo com base nos pré-construídos e no propósito comunicativo que ele 
intenciona. Por sua vez, cabe ao interlocutor (B) - um sujeito ou um auditório - reconstruir os sentidos provenientes dos objetos construídos por A. Para isso, B terá de interpretar o conteúdo referencial com base nos seus próprios pré-construídos culturais e sociais, bem como em seu propósito comunicativo.

Para Adam (2011, p. 113), uma representação discursiva é “[...] a expressão de um ponto de vista [PdV]". Portanto, para interpretá-la, devemos atentar para a representação que é construída pelo conteúdo proposicional. Em vista disso, percebe-se que a Rtd é argumentação e se manifesta no texto (ANT - argumentação no texto) como assevera Pinto (2010, p. 85) ao afirmar que:

Dessa forma, a argumentação, no sentido mais amplo preconizado por Adam, tanto pode envolver os diversos tipos de sequência - não apenas a argumentativa, como também poderá estar relacionada às imagens do enunciador construídas textualmente.

Nesse sentido, Passeggi (2012, p. 232) ressalta que as representações discursivas "[...] são de natureza linguística, manifestadas nos/pelos textos". Desse modo, a representação enquanto referência do enunciador, do leitor ou dos assuntos tratados só pode ser percebida na/pela produção co(n)textual de sentidos, o que implica uma (re)construção do sentido por parte do interpretante. Sobre isso, Adam (2011, p. 114) afirma que:

É o interpretante que constrói a Rd a partir dos enunciados (esquematização), em função de suas próprias finalidades (objetivos, intenções) e de suas representações psicossociais da situação, do enunciador e do mundo do texto, assim como de seus pressupostos culturais.

Assim, ao construir uma Rtd em um dado texto, recai sobre o leitor/interpretante o papel de (re)construí-la com base em suas representações (psíquicas, sociais, culturais etc.), a fim de obter os resultados semânticos ali atribuídos e atendendo a um propósito argumentativo. Não significa dizer que o interpretante deverá agir simetricamente ao locutor, mas ele é solicitado a desenvolver uma atividade semelhante de (re)construção do sentido (ADAM, 2011).

Santos (2016) evidencia que apesar de não mencionarem o termo "representação discursiva", entende que a ideia de auditório desenvolvida por Perelman e Olbrechts-Tyteca refere-se às imagens e ou representações discursivas que o orador constrói de seu ouvinte/leitor, de acordo com suas intenções e propósitos. Para Perelman e Olbrechts-Tyteca (1999, p. 189), a 
argumentação é um ato persuasivo, já que tenta investigar a força argumentativa dos enunciados com o objetivo de conseguir a adesão do auditório. O ouvinte é o conjunto daqueles sobre os quais o orador quer influir, pela sua argumentação, é necessário considerar que esse conjunto é uma imagem ou representação que o orador cria, segundo seus objetivos e intenções.

Nessa perspectiva, Damele (2014) afirma que o auditório imediato de um juiz será constituído pelas partes envolvidas no processo. De um modo geral, esse auditório será formado por todos os operadores jurídicos, ou por aqueles a quem possa interessar o caso em questão: “[...] os juízes das instâncias superiores, os advogados ou os juízes dos casos futuros chamados a confrontar-se com os precedentes, e a jurisprudência, os juristas" (DAMELE, 2014, p. 225). Finalmente, esse auditório também poderá vir a ser constituído, em um nível máximo de generalização, por toda a opinião pública, ou pelo menos, por todos aqueles interessados em questões jurídicas lato sensu: “[...] não só os juristas, mas também os políticos, os jornalistas, mais ou menos especializados, e os possíveis comentadores. [...] o auditório do juiz será, portanto, necessariamente, social e historicamente contextualizado" (DAMELE, 2014, p. 225).

Desse modo, o processo de construção das Rtd com valor argumentativo leva em conta as finalidades, as intenções, os objetivos e os pressupostos históricos e culturais do interpretante. Assim, ela é semanticamente construída pelo falante, que realiza um trabalho interpretativo e coerente que permite as interligações das unidades textuais.

\section{Caracterização do gênero acórdão como ação social}

Os textos por serem também produtos de normas e convenções determinadas pelas práticas sociais, as formas de interação, reprodução e alteração social dos gêneros constituem "ações sociais, no sentido de que se gênero representa ação, deve envolver situações e motivação, porque ações humanas, simbólicas ou de outro tipo, são interpretadas somente num contexto de situação e pela atribulação de motivação" (MILLER, 2012, p. 39).

Nesse sentido, os gêneros enfatizam a ação social, visto que ele pode representar uma ação retórica triplicada, que requer ações próprias de uma comunidade em que nós aprendemos a agir retoricamente através do uso de 
tipos de discurso socialmente adequados aos vários contextos e circunstâncias da vida.

Bazerman (2011) define gênero como fato social ao afirmar que identificar gênero historicamente conduz o conceito de gênero de um fato essencial que reside nos textos a um fato social, real, na medida em que as pessoas o tomam como real e em que essa realidade sociopsicológica influi na sua compreensão e no seu comportamento, dentro da situação como elas a percebem.

Em vista disso, defende a ideia de que os indivíduos avançam em seus interesses, moldam suas significações no interior de complexos sistemas sociais, atribuem valores e avaliam consequências de interações verbais ao utilizarem diferentes gêneros. Tal fato ocorre com os gêneros jurídicos em que a organização social e as relações de poder se relacionam em um contexto sociorretórico a fim de compreender o funcionamento social e histórico do direito em ações sociais.

Isso ocorre com o gênero forense acórdão, definido por lei, apresenta, em geral, um aspecto formulaico ${ }^{1}$ e é produzido a partir de fatos sociais, pertencente a uma comunidade discursiva jurídica. Conforme o art. 204, do Código de Processo Civil Brasileiro, recebe a denominação de AC o julgamento colegiado (seção, câmara, plenário, turma etc) proferido pelos tribunais. É resultado das manifestações individuais dos membros do colegiado, que manifestam seu sentir por meio dos votos (DONIZETTI, 2017).

Esse gênero contempla a data de publicação e página do Diário Oficial, é o ato pelo qual se torna pública a decisão por meio de um órgão público responsável pelas publicações do Poder Judiciário. Os Órgãos julgadores são as Turmas dos tribunais; o Relator é o desembargador/ministro que apresenta competência de ordenar e dirige os processos que lhe sejam distribuídos, até a redação do AC; o Revisor é um Desembargador/ministro que participa, também, do julgamento e, geralmente, inicia a votação, seguindo-se o voto do Revisor e dos demais desembargadores/ministros, pela ordem de antiguidade. $\mathrm{O}(\mathrm{s})$ recorrente(s) e recorrido(s) são as partes que litigam.

Podem ser reclamante/exequente (autor) ou o reclamado/executado (réu). A Ementa é o resumo que se faz dos princípios expostos no AC. O relatório contém os nomes das partes, a suma do pedido e da resposta do réu,

\footnotetext{
${ }^{1}$ O termo formulaico é utilizado por Marcuschi (2008, p. 37) para se referir a gêneros que possuem uma estrutura retórica preestabelecida, onde quase não há espaço para o estilo do autor, como os gêneros jurídicos, por exemplo.
} 


\section{$\mathrm{EI} D \mathrm{dA}$}

Revista Eletrônica de Estudos Integrados em Discurso e Argumentação, Ilhéus, n. 18, abr.2019.

registra-se as principais ocorrências havidas no andamento do processo. Serve de base para o julgamento.

No que tange ao voto, a fundamentação é a posição individual do Desembargador manifestada no julgamento do processo. É nessa ocasião que serão analisadas as questões de fato e de direito formuladas pelas partes. Analisa-se o Juízo de Conhecimento - a análise dos pressupostos objetivos e subjetivos de uma ação. É nessa ocasião que se observa a adequação do recurso, ou seja, se é cabível ou não. Já os pressupostos subjetivos dizem respeito à legitimidade e ao interesse recursal. E o Juízo de Mérito, consiste na perquirição acerca da presença do defeito da decisão suscitada pelo recorrente na peça recursal. É a ocasião em que analisa a razão do inconformismo.

Por fim, a Conclusão, que é a parte final do AC em que será declarada a vontade concreta do julgador. É nesse momento que o relator-produtor resolve as questões que as partes lhe submeteram. A Data é a certificação do dia do julgamento que vem seguida da assinatura do seu relator. É a partir da data da publicação do AC que inicia um novo prazo para interposição de outro recurso, se for o caso.

Vale salientar que cada voto do desembargador segue a ordem legal disposta no art. 489 do Código de Processo Civil que enumera os elementos essenciais da sentença: o relatório, os fundamentos e o dispositivo.

Desse modo, o gênero acórdão como ação social não é concebido como modelo estanque ou como estruturas rígidas, devido ser forma retórica dinâmica que se modifica constantemente de acordo com as necessidades sociocognitivas dos usuários da língua.

3. As Representações textuais-discursivas do réu e os termos de emoção no Acórdão do pedido de soltura de José Dirceu na Operação Lava Jato

Plantin (2010) assegura que é possível argumentar emoções, isto é, fundar no interlocutor um "dever-sentir", a partir de enunciados que são orientados em direção a uma determinada emoção. A análise de como se dá essa argumentação parece extremamente relevante. $O$ autor também afirma que as figuras retóricas devem ser tratadas não como ornamento, mas "[...] como instrumentos destinados a suscitar a emoção no interlocutor, os princípios geradores da emoção" (PLANTIN, 2010, p. 65). 
No entanto, o direito se distanciaria do dever-sentir por estar baseado no campo de uma racionalidade strictu sensu, não lhe sendo admitida a intromissão de qualquer elemento exógeno. Nussbaum (1996) assevera que uma possível reação em face da tentativa de introduzir elementos emotivos no âmbito jurídico seria alegar a sua completa irracionalidade e, por isso, a impossibilidade de levá-los em consideração: "existe um famoso lugar-comum no sentido de que o direito é baseado na razão e não na paixão" (NUSSBAUM, 1996, p. 25). É possível chamar a tradição legal que compreende as emoções como estranhas ao direito de proposta "não emotiva". Porém, um tal posicionamento simplesmente desqualifica o debate teórico e prático acerca do direito: "[...] em primeiro lugar, o direito sem apelo à emoção é virtualmente impensável" (op.cit., p. 25).

Para amostragem, selecionamos o Acórdão referente ao (habeas corpus - processo $n^{\circ}$ 5034542-82.2015.4.04.0000/PR), da Egrégia $8^{a}$ Turma do Tribunal Regional Federal da $4{ }^{\text {a }}$ Região, publicado em 14 de outubro de 20152 . Trata-se de julgamento de pedido de habeas corpus da prisão preventiva de José Dirceu, ex-ministro chefe da casa civil na gestão do presidente Luiz Inácio Lula da Silva, cuja pretensão era o pedido de liberdade provisória do paciente (réu). A ação foi julgada improcedente, ou seja, em desfavor do réu, por ser reincidente e está respondendo a outros processos no Supremo Tribunal Federal por corrupção ativa e passiva (Mensalão, Dossiê, bingos e Operação Lava Jato).

Para a análise linguística das emoções no Acórdão recorremos a Plantin (2011), que propõe uma categoria de termos, os termos de emoção, que formam o núcleo dos enunciados de emoção, cuja forma semântica é a seguinte: [Lugar psicológico (= Experimentador) + Termo de emoção + Fonte da emoção]. Rodrigues e Passeggi (2016) ressaltam que os termos de emoção são uma das realizações linguísticas para a designação de uma determinada emoção, que poderia ser expressa por outros termos.

É relevante descrever a emoção, em moldes linguísticos (termo de emoção), fundamentada na argumentação. Conforme prescreve Plantin (2010), esses termos de emoção são designados de forma direta ou indireta. No corpus selecionado, elegemos a designação direta dos termos de emoção a partir de substantivos de emoção. Vejamos agora como os termos de emoção contribuem para a Rtd do réu no Acórdão analisado:

\footnotetext{
${ }^{2}$ Disponível em: https://www.conjur.com.br/dl/trf-mantem-prisao-dirceu-dominio-fato.pdf
} 


\section{Quadro 1- Termos de emoção}

\section{Termos de emoção}

O nível de corrupção que está sendo descoberto na Petrobras, envolvendo políticos, empresários e servidores públicos, é estarrecedor.

" O que é isso? Em que país vivemos? Os bandidos perderam a noção das coisas! Como podem se apropriar desse montante?", questionou incrédulo o desembargador convocado Walter de Almeida Guilherme.

O desembargador Newton Trisotto, relator de inúmeros habeas corpus relacionados à investigação chegou a afirmar que 'poucos momentos na história brasileira exigiram tanta coragem do juiz como esse que vivemos nos últimos anos. Coragem para punir os políticos e os economicamente fortes, coragem para absolvê-los quando não houver nos autos elementos para sustentar um decreto condenatório'.

Havendo fundada razão diante das circunstâncias concretas, mostra-se inevitável a adoção de medidas amargas que cessem a cadeia delitiva e sirvam de referencia aos que tratam com desprezo às instituições públicas, sempre acreditando na impunidade.

Ministro Jorge Mussi, também manifestou sua indignação reproduzindo frase do ministro Gilmar Mendes, do Supremo Tribunal Federal, ' levando-se em consideração o volume de recursos envolvidos na operação Lava Jato, o mensalão deveria ter sido julgado no juizado de pequenas causas'.

\section{Fonte: Dados da pesquisa}

Os elementos lexicais assinalados no Acórdão, gênero jurídico recursal, apresentam termos de emoção que embasam a representação textual do réu como mentor de uma organização criminosa ao demonstrar a periculosidade dele. Isso se dá através dos lexemas de emoção "estarrecedor", "incrédulo", “coragem”, “amargas”, “desprezo” e “indignação”. Rodrigues et al. (2017) afirmam que um lexema pode variar em função de uma gama de possibilidades de uso, conforme os valores a que esteja associado, nas várias situações enunciativas em que possa vir a ser empregado pelo falante.

Percebe-se que os termos de emoção apresentados no Acórdão aumentam sentimentos de percepção de risco de conceder o habeas corpus ao réu (José Dirceu) e gera demanda por novos mecanismos de segurança, promovendo significativas alterações jurídicas. Isto porque, o medo torna os indivíduos mais propensos a apoiar medidas de segurança em detrimento de outras liberdades importantes.

Plantin (2011, p. 187) enfatiza que estados emocionais internos, manifestados físico ou psiquicamente, só interessam aqueles que são formatados pela linguagem: "as emoções são o que significamos que elas são". Ainda, há outro aspecto que o autor destaca:

Abordar as emoções sob o ângulo da argumentação é extremamente produtivo. A realidade discursiva das emoções aparece de forma particularmente evidente quando a emoção está não somente no debate - ela sempre está - mas em 
debate. A argumentação tem necessidade das emoções e as emoções têm necessidade da argumentação, pois é pela argumentação que elas são produzidas em geral, e sustentadas em certos casos. (PLANTIN, 2011, p. 187).

É nesse sentido que o autor explicita a construção argumentativa das emoções. O enfoque de Plantin (2010, 2011) é particularmente importante no caso do discurso jurídico, pois permite delinear a relação entre emoções e argumentação. Com efeito, os termos de emoção acima descritos demonstram que a relação entre o direito e as emoções é muito mais profunda do que se pode, a princípio, imaginar.

Os termos de emoção descritos, no acórdão em análise, evidenciam a onipresença da argumentação no quadro explicativo abaixo da esquematização de Grize (1990), a partir da imagem do alocutário (réu - José Dirceu - mentor de uma organização criminosa) sem estruturas argumentativas. Vejamos o Quadro 2:

Quadro 2 - Esquematização

\begin{tabular}{|c|c|c|}
\hline Grize & Adam & Definição \\
\hline $\begin{array}{l}\text { Imagem do } \\
\text { locutor: } \\
\text { im(A) }\end{array}$ & $\begin{array}{l}\text { Representação } \\
\text { discursiva de si }\end{array}$ & $\begin{array}{l}\text { Também chamada de ethos, refere-se à imagem que o } \\
\text { locutor constrói de si mesmo pelas palavras que evoca } \\
\text { em seu texto/discurso. Com bae em Adam (2011b, p. } \\
\text { 107), podemos entender que a Rd de si está associada a } \\
\text { "função (lugar) e o(s) papel(eis) que o [orador] assume, } \\
\text { com seus fins próprios, seus pré-construídos culturais } \\
\text { representações da situação de enunciação, do objeto do } \\
\text { discurso, de seu auditório (B) e as representações } \\
\text { psicossociais de si mesmo" }\end{array}$ \\
\hline $\begin{array}{l}\text { Imagem do } \\
\text { alocutário: } \\
\text { im(B) }\end{array}$ & $\begin{array}{l}\text { Representação } \\
\text { discursiva do } \\
\text { alocutário }\end{array}$ & $\begin{array}{l}\text { Associada a Rd que o locutor faz do alocutário (b), essa } \\
\text { representação é percebida pela dialogicidade na } \\
\text { interação comunicativa. Nesse sentido, Amossy (2005, } \\
\text { p. 124) afirma que "o bom andamento da troca exige } \\
\text { que à imagem do auditório corresponda uma imagem } \\
\text { do orador". Assim, por ser o alocutário um coconstrutor } \\
\text { da representação presente no texto/discurso, a } \\
\text { constante troca de experiências singulares se } \\
\text { presentifica nos enunciados, revelando a imagem do } \\
\text { alocutário (GRIZE, 1996; PASSEGGI, 2001) }\end{array}$ \\
\hline $\begin{array}{l}\text { Imagem do } \\
\text { tema } \\
\text { tratado: } \\
\operatorname{im}(\mathrm{T})\end{array}$ & $\begin{array}{l}\text { Representação } \\
\text { discursiva do } \\
\text { tema tratado }\end{array}$ & $\begin{array}{l}\text { Constituem o que Passeggi (2001, p. 249-250) chama de } \\
\text { "conteúdos do manifesto da esquematização e } \\
\text { remetem diretamente às operações lógico-discursivas } \\
\text { de sua construção". As operações a que o autor se } \\
\text { refere concernem à escolha e ao arranjo das palavras } \\
\text { que os interlocutores fazem, permitindo a construção } \\
\text { a reconstrução das representações discursivas dos } \\
\text { conteúdos referenciais evidenciados no e pelo texto } \\
\text { (ADAM, 2011; QUEIROZ, 2013). }\end{array}$ \\
\hline
\end{tabular}

Fonte: Aquino (2015, p. 63) 
Nessa perspectiva, a esquematização é uma específica forma de organizar a realidade, fazê-la compreensível e, assim, transmitir, linguisticamente, as emoções. Com isso, esse trabalho caracteriza a Rtd do réu com valor argumentativo a partir dos termos de emoção, com base nas categorias semânticas de referenciação, predicação e modificação.

As categorias sintático-semânticas da construção das Rtd constituem-se de elementos linguísticos que aparecem materializados no texto através de substantivos, adjetivos, verbos, advérbios, pronomes, articulando-se entre si e formando um todo significativo, conforme ilustradas no Quadro 3:

\section{Quadro 3 - Exemplificação da Representação Textual-Discursiva}

\begin{tabular}{|c|c|}
\hline $\begin{array}{l}\text { Categorias } \\
\text { sintático- } \\
\text { semânticas }\end{array}$ & Representação textual-discursiva \\
\hline REFERENCIAÇÃO & $\begin{array}{ll}\text { - } & \text { Indiciado } \\
\text { - } & \text { Investigado } \\
\text { - } & \text { Paciente } \\
\text { - } & \text { Réu } \\
\end{array}$ \\
\hline PREDICAÇÃO & $\begin{array}{l}\text { - Demonstra não só a sua indiferença perante o direito, mas } \\
\text { também sua intenção de continuar praticando crimes, } \\
\text { revelando maior à ordem pública e a necessidade de cessar a } \\
\text { atividade criminosa... } \\
\text { - Encontra-se justificada a periculosidade social. } \\
\text { - } \frac{\text { Resultaram vultuosos prejuízos à sociedade de economia }}{\text { mista e , na mesma proporção, em seu enriquecimento ilícito e }} \\
\text { de terceiros.. } \\
\text { - Justifica-se a decretação da prisão preventiva, para a garantia } \\
\text { - da ordem pública e do risco de reiteração criminosa.. } \\
\text { - Interferir na colheita de provas... } \\
\text { - Encontrava-se cumprindo pena imposta na Ação Penal/STF nº } \\
470 . . .\end{array}$ \\
\hline MODIFICAÇÃO & $\begin{array}{l}\text { - Com posição de preponderância no grupo... } \\
\text { - Como controlador e beneficiário criminoso... } \\
\text { - } \text { Representante das empresas envolvidas em organização } \\
\text { criminosa... } \\
\text { - Mentor de organização criminosa... }\end{array}$ \\
\hline
\end{tabular}

Fonte: Dados da pesquisa

A primeira categoria, a referenciação do réu, é tematizada através da periculosidade dele por ser mentor de uma organização criminosa. Além da reincidência em práticas criminosas e de se encontrar como réu em outros processos na instância máxima da corte brasileira, o STF, em escândalos de corrupção e contra a administração pública. Essas designações reforçam a 


\section{$\mathrm{El} \square \mathrm{dA}$}

necessidade da prisão preventiva em virtude do réu ter praticado atos ilícitos em um curto espaço de tempo.

Nesse sentido, constata-se que as expressões referenciais contribuem mais estreitamente para a construção da representação textual-discursiva do réu no texto forense. Considerando que a escolha do material linguístico empregado durante a produção textual reflete, antes de tudo, àquilo que o locutor quer passar ao seu interlocutor, ou seja, suas intenções, seus objetivos. Os operadores do direito tem a preocupação de, através dos fatos apresentados, da legislação e da jurisprudência, apresentar ao seu leitor, argumentos consistentes e fundamentados de modo a não restarem dúvidas sobre a decisão tomada no documento.

Vale ressaltar que o discurso jurídico apresenta uma variedade de termos técnicos utilizados em contextos comunicativos específicos. Por isso, Santos, Pinto e Cabral (2016, p. 169) afirmam que é importante verificar como os processos referenciais exigem o acionamento de conhecimentos prévios, compartilhados pelo entorno sociocognitivo e cultural, para reconstruir os objetos do discurso e, assim, construir sentidos. Os gêneros jurídicos visam à adesão de terminada tese por destinatários/interlocutores da prática jurídica, as estratégias referenciais utilizadas que podem vir a ter.

Dessa forma, observamos uma diversidade de expressões próprias do léxico jurídico para designar o objeto de discurso em análise, como: “indiciado”, “investigado", "paciente” e "réu”. Há um critério de organização no texto forense para a utilização de cada termo, que não pode ser comparado ou confundido, ou seja, os termos "indiciado" ou "réu" não se confundem, pois, apesar de fazerem referência ao mesmo sujeito, são utilizados em situações distintas.

Quanto à predicação, os verbos conjugados no presente ("justifica", "demonstra" e "encontra”) e a locução verbal ("encontrava-se cumprindo") marcam as primeiras ações do réu. Já o uso da locução verbal indica um processo não acabado, que expressa um continuum ou uma constância das ações. A escolha dos predicados focalizou o estado de ação do reú em praticar atos ilícitos mesmo estando preso, uma vez que foi condenado na Ação Penal 470 (pena de 7 anos e 11 meses de prisão).

Observamos que em todas as ocorrências citadas a Rtd do réu se construiu elencando aspectos de periculosidade acentuada por ser mentor de uma organização criminosa. Identificamos em todas as ocorrências que as 
$\mathrm{EI} D \mathrm{dA}$

Revista Eletrônica de Estudos Integrados em Discurso e Argumentação, Ilhéus, n. 18, abr.2019.

designações utilizadas pelo desembargador-relator contribuíram para a construção das Rtd do réu no texto jurídico, realçando aspectos negativos desse objeto no discurso.

Como podemos observar no Quadro 4, a Rtd do referente foi construída a partir de seus modificadores que desempenharam nos enunciados função atributiva ("preponderância no grupo", "controlador e beneficiário criminoso", "representante das empresas envolvidas em organizações criminosas" e "mentor de organização criminosa"). Esses modificadores contribuem para a construção de sentido do referente e permitem ao leitor visualizar a imagem do objeto que o enunciador quer evidenciar.

Com isso, o objeto de discurso recebe como seus modificadores adjetivos modalizadores asseverativos, ou seja, cada expressão utilizada no enunciado veicula e atribui um valor de verdade às propriedades do objeto. Essas expressões qualificadoras que têm como objetivo agregar valor ao referente e reforçar o posicionamento do enunciador. Essa estratégia, além de incorporar ao objeto traços valorativos, intenciona induzir o leitor sobre a veracidade imputada no enunciado.

Destarte, a sucinta análise do Acórdão nos evidencia que é através das escolhas linguísticas empregadas no texto que o enunciador revela seus verdadeiros objetivos e posicionamentos. No entanto, essas escolhas não são aleatórias, mas estratégias importantes para o valor argumentativo da Rtd do réu e a influência dos termos de emoção neste processo de construção do sentido no contexto forense.

\section{Considerações finais}

Considerando o objetivo geral do nosso estudo de analisar as representações textuais-discursivas com valor argumentativo e a sua articulação com os termos de emoções, percebemos que além do material linguisticamente utilizado na construção do texto desse gênero como ação social, o valor argumentativo das Rtd se faz presente em virtude do propósito dessa ação de linguagem no contexto jurídico ser pautada em fatos sociais.

Para a investigação do processo de construção da Rtd do réu no Acórdão, utilizamos as categorias semânticas das Rtd. Essas categorias materializam-se no texto através dos substantivos, adjetivos, verbos, advérbios, que corresponderam aos elementos linguístico-discursivos. Entendemos que os objetos do discurso são construídos a partir de um posicionamento do 
enunciador frente às razões que o motivaram. Nesse sentido, constatamos que é a partir da construção desses objetos que o enunciador fundamenta sua tese de modo a persuadir e convencer seu auditório/leitor.

Tal constatação "abre caminho" para que diversas formas e procedimentos sejam reconhecidos como argumentativos, uma vez que os objetos são construídos a partir de um posicionamento do enunciador frente às razões que o motivaram, utilizando as imagens como a própria argumentação. Assim elas não desempenham apenas funções discursivas que auxiliam na interpretação.

Ademais, ao contrário do que poderia aparentar à primeira vista, os termos de emoções participam em vários níveis da constituição do direito e de sua prática, de modo que uma abordagem que também privilegie o seu estudo permitirá uma melhor compreensão da dinâmica do fenômeno jurídico, possibilitando, proveitosamente, novas formas de crítica teórica à maneira pela qual o direito é estruturado.

Diante do exposto e da importância social do discurso jurídico e, em especial, do Acórdão e da Operação Lava Jato na vida dos cidadãos brasileiros, percebemos a relevância em desenvolver pesquisas interdisciplinares entre direito e letras. Nesse contexto, conforme Lourenço (2017, p. 55), diz respeito a contribuição que os trabalhos desenvolvidos por linguistas podem dar ao aprimoramento da compreensão do texto jurídico, ao ensino de língua portuguesa durante a graduação aos futuros operadores do direito, auxiliando-os na produção de seus próprios textos, no que diz respeito a atribuir maior eficácia do poder de persuasão.

\section{Referências}

ADAM, Jean-Michel. A Linguística textual: introdução à análise textual dos discursos. Tradução: Maria das Graças Soares Rodrigues, João Gomes da Silva Neto, Luis Passeggi e Eulália Vera Lúcia Fraga Leurquin. 2. ed. rev. e aum. São Paulo: Cortez, 2011.

. Imagens de si e esquematização do orador: Pétain e De Gaulle em junho de 1940. In : AMOSSY, Ruth (Org.). Imagens de si no discurso: a construção do ethos. Tradução: Dilson Ferreira da Cruz, Fabiana Komesu e Sírio Possenti. São Paulo: Contexto, 2005. p. 93-117.

- Introduction aux problèmes du texte. In:

(Org.). Faire texte.

Frontières textuelles et opérations de textualisation. Besançon: Presses Universitaires de Franche-Comté, 2015. p. 12-33. 
AMOSSY, Ruth (Org.). Imagens de si no discurso: a construção do ethos. Tradução: Dilson Ferreira da Cruz, Fabiana Komesu e Sírio Possenti. São Paulo: Contexto, 2005.

AQUINO, Lucélio D. Representações discursivas de Lula nas capas das revistas Época e Veja. 232f. Tese (Doutorado em Estudos da Linguagem) Natal: PPgEL/UFRN, 2015.

BAZERMAN, Charles. Gêneros textuais, tipificação e interação social. Organização e Tradução: Judith Chambliss Hoffnagel. 2. ed. São Paulo: Cortez, 2011.

DAMELE, Giovanni. Notas sobre o papel da retórica nas teorias da argumentação jurídica. Revista Brasileira de Filosofia, São Paulo, ano 62, v. 240, p. 222-239, 2014.

DONIZETTI, Elpídio. Novo Código de Processo Civil Comentado. São Paulo: Atlas, 2017.

GIL. Antonio Carlos. Como elaborar projetos de pesquisa. 5. ed. São Paulo: Atlas, 2010.

GRIZE, Jean-Blaise. Logique et langage. Paris: Ophrys, 1990.

. Logique naturelle et communications. Paris: PUF, 1996.

LAMY, Marcelo. Metodologia da pesquisa jurídica: técnicas de investigação, argumentação e redação. Rio de Janeiro: Elsevier, 2011.

LOURENÇO, Maria das Vitórias N. Argumentação na petição inicial. Curitiba: CRV, 2017.

MARCUSCHI, Luiz Antônio. Produção textual, análise de gêneros e compreensão. São Paulo: Parábola Editorial, 2008.

MILLER, Carolyn Rae. Gênero textual, agência e tecnologia. Organização e tradução: Judith Chambliss Hoffnagel. Recife: EDUFPE, 2012.

NUSSBAUM, Martha. Emotion in the language of judging. St. John's Law Review, v. 70, n. 1, p. 23-30, 1996.

OLIVEIRA, Maria Marly. Como fazer pesquisa qualitativa. Petrópolis: Vozes, 2013.

PASSEGGI, Luis. Estruturação sintático-semântica dos conteúdos discursivos: categorias descritivas da lógica natural para a linguística. In: PASSEGGI, Luis; OLIVEIRA, Maria do Socorro (Org.). Linguística e Educação: gramática, discurso e ensino. São Paulo: Terceira Margem, 2001. p. 245-269.

- As representações discursivas na pesquisa autobiográfica: uma metodologia de análise semântica. In: ABRAHÃO, Maria H. M. B.; PASSEGGI, Maria da Conceição (Org.). Dimensões epistemológicas e metodológicas da pesquisa (auto)biográfica: tomo I. Natal: EDUFRN; Porto Alegre: EDIPURCS; Salvador: EDUNEB, 2012. p. 231-252.

- Uma abordagem do discurso jurídico do ponto de vista da linguística do texto e do discurso. In: Anais do III Seminário Internacional de Estudos Sobre Discurso e Argumentação (III SEDiAr) - Universidade Federal de Sergipe, 2016, Aracaju. Ilhéus: Editus, 2016. Disponível em: http://www.sediar.com. Acesso em: 21 mar. 2017 
PERELMAN, Chaïm; OLBRECHTS-TYTECA, Lucie. Tratado da argumentação: a nova retórica. São Paulo: Martins Fontes, 1999.

PINTO, Rosalice. Como argumentar e persuadir? Práticas: política, jurídica, jornalística. Lisboa: Quid Juris, 2010.

PLANTIN, Christian. As razões das emoções. In: MENDES, Emília; MACHADO, Ida Lúcia. As emoções no discurso. Tradução: Emília Mendes et al. Campinas: Mercado das Letras, 2010, p. 57-80. v. 2

. Les bonnes raison des émotions: principes et méthode pour l'étude du discours émotionné. Berne: Peter Lang, 2011.

QUEIROZ, Eliete. Representações discursivas no discurso político. "Não me fiz sigla e legenda por acaso": o discurso de renúncia do senador Antonio Carlos Magalhães. (30/05/2001). 2013. Tese (Doutorado em Linguística Aplicada), Universidade Federal do Rio Grande do Norte, Natal, 2013.

RODRIGUES, Maria das Graças Soares et al. Ateliê de escrita: a emoção como fonte motivadora. In: MARQUESI, Sueli Cristina, PAULIUKONIS, Aparecida Lino e ELIAS, Vanda Maria. Linguística textual e ensino. São Paulo: Contexto, 2017.

RODRIGUES, Maria das Graças Soares; PASSEGGI, Luis. "Tentam colocar medo no povo": vozes, emoções e representações em um texto jornalístico. São Paulo: EDUC/IP-PUC-SP, 2016. p. 259-272.

RODRIGUES, Maria das Graças Soares; PASSEGGI, Luis; SILVA NETO, João Gomes (Org.). "Voltarei. O povo me absolverá...": a construção de um discurso político de renúncia. In: ADAM, Jean-Michel et al. (Org.). Análises textuais e discursivas: metodologias e aplicações. São Paulo: Cortez, 2010. p. 150-195.

SANTOS, Leonor Werneck; PINTO, Rosalice; CABRAL, Ana Lúcia Tinoco. Referenciação em textos jurídicos: da argumentação da língua à argumentação no gênero. In: PINTO, Rosalice et al. (Org.). Linguagem e direito: perspectivas teóricas e práticas. São Paulo: Contexto, 2016. p. 165-178.

SANTOS, Maria de Fátima dos. Representações discursivas de vítima e agressor em textos de inquéritos sociais. 2016. 193f. Tese (Doutorado em Estudos da Linguagem) Natal: PPgEL/UFRN, 2016.

\section{Forma de citação sugerida}

FREITAS, Fernanda Isabela Oliveira; PASSEGGI, Luis Álvaro Sgadari. Os termos de emoção no acórdão do pedido de soltura de José Dirceu na Operação Lava Jato e as Representações Textual-Discursivas. EID\&A - Revista Eletrônica de Estudos Integrados em Discurso e Argumentação, Ilhéus, n. 18, p. 20-37, abr.2019. DOI dx.doi.org/10.17648/eidea-18-2195. 